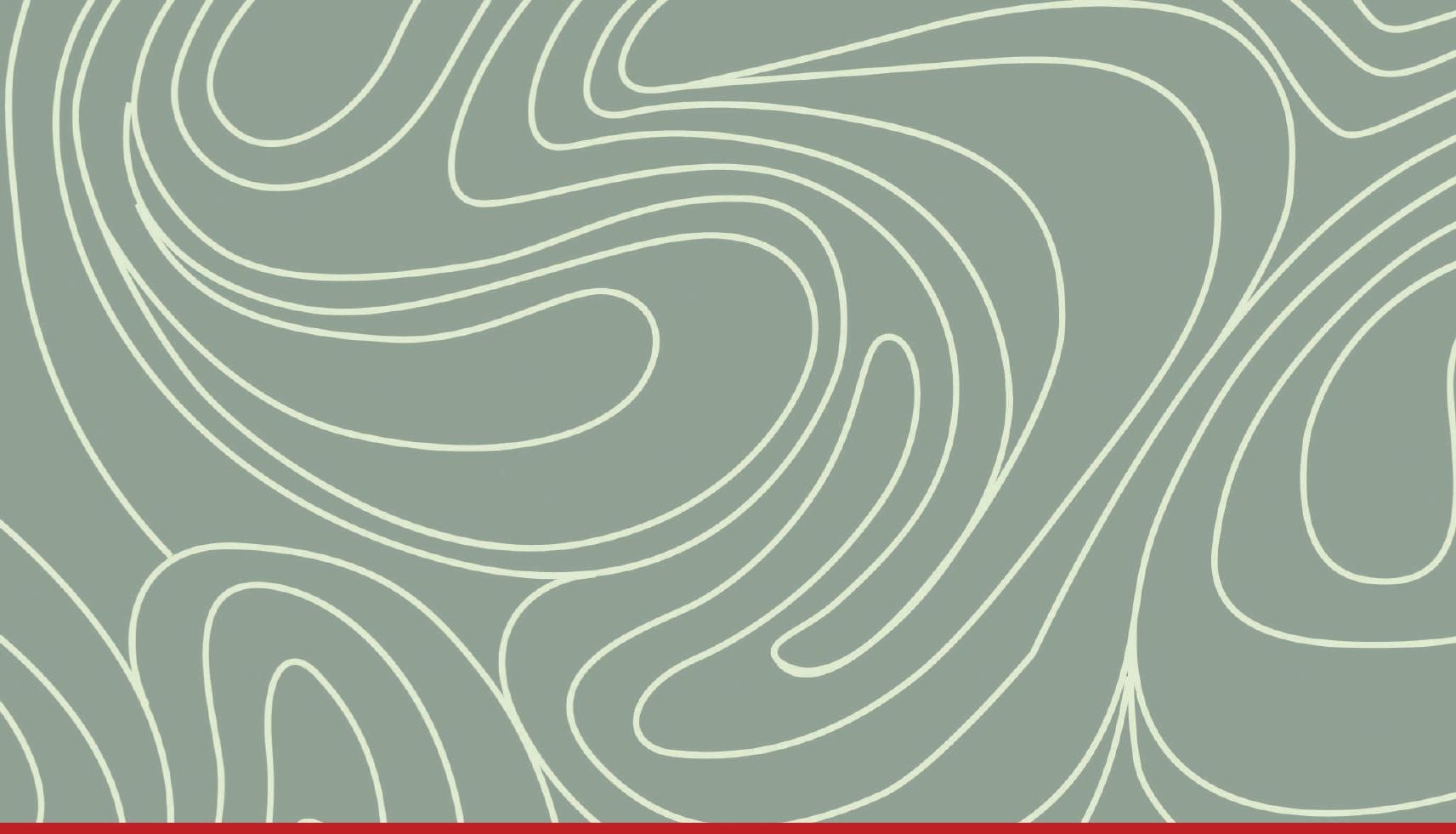

Changing Mobilities

\title{
HYBRID MOBILITIES
}

\section{TRANSGRESSIVE SPATIALITIES}

Edited by

Nadine Cattan and Laurent Faret

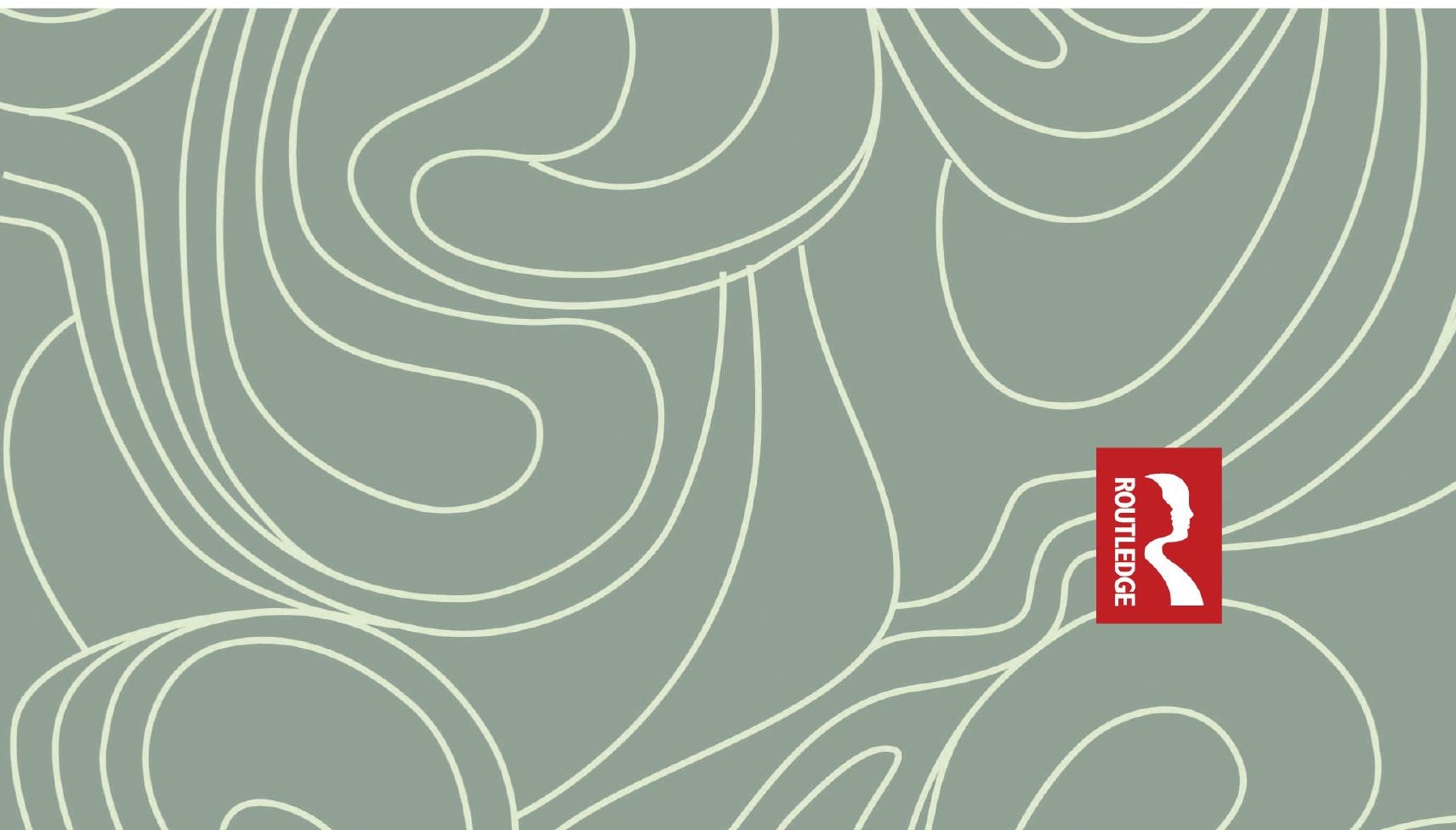




\section{Hybrid Mobilities \\ Transgressive Spatialities}

\section{Edited by \\ Nadine Cattan and Laurent Faret}


First published 2022

by Routledge

2 Park Square, Milton Park, Abingdon, Oxon OX14 4RN

and by Routledge

605 Third Avenue, New York, NY 10158

Routledge is an imprint of the Taylor \& Francis Group, an informa business

(C) 2022 selection and editorial matter, Nadine Cattan and Laurent Faret; individual chapters, the contributors

The right of Nadine Cattan and Laurent Faret to be identified as the authors of the editorial material, and of the authors for their individual chapters, has been asserted in accordance with sections 77 and 78 of the Copyright, Designs and Patents Act 1988.

All rights reserved. No part of this book may be reprinted or reproduced or utilised in any form or by any electronic, mechanical, or other means, now known or hereafter invented, including photocopying and recording, or in any information storage or retrieval system, without permission in writing from the publishers.

Trademark notice: Product or corporate names may be trademarks or registered trademarks, and are used only for identification and explanation without intent to infringe.

British Library Cataloguing-in-Publication Data

A catalogue record for this book is available from the British Library

Library of Congress Cataloging-in-Publication Data

A catalog record has been requested for this book

ISBN: 978-0-367-90283-4 (hbk)

ISBN: 978-1-032-07108-4 (pbk)

ISBN: 978-1-003-02356-2 (ebk)

DOI: $10.4324 / 9781003023562$

Typeset in Times New Roman

by Newgen Publishing UK 


\section{Contents}

List of images $\quad$ xi

List of figures xii

List of tables xiii

Notes on the contributors xiv

Acknowledgments xvi

Introduction: when mobilities construct spatialities 1

NADINE CATTAN AND LAURENT FARET

\section{PART I}

A relational approach: insights into the building of sociospatial concepts

1 Tenements in New York and riads in Marrakesh: mobilities and the new paradigm of heritagization MARIA GRAVARI-BARBAS

2 Urban mobilities and power: social exclusion by design in the city

OLE B. JENSEN

3 Rethinking 'ethnic neighborhoods' after the mobility turn NANCY L. GREEN

4 Clouds and movements PANOS BOURLESSAS AND ALBERTO VANOLO

5 Transportation vehicles in Africa: between autonomy and the administration of space 


\section{PART II}

Spatial practices of the city: power relations and agency

6 Migrant women servants in Amman and backpackers in Bangkok: the 'walking interviews' method for studying mobile groups in cities

DAPHNÉ CAILLOL AND BRENDA LE BIGOT

7 Padlocks as obscure objects of tourism: an emotional imprint in the city of love NADINE CATTAN AND CAMILLE SCHMOLL

8 Transgressing the city-state: migrant domestic workers in Singapore RACHEL SILVEY, DANIĖLE BÉLANGER, RESMI SETIA MILAWATI, AND KAYOKO UENO

9 Everyday mobility and the social divisions of space: a space-time analysis of Mexico City

SALOMÓN GONZÁLEZ ARELLANO AND SOCORRO FLORES GUTIÉRREZ

\section{PART III}

Mobility schemes, values, and norms: a sociopolitical perspective

10 Immobility as a migration-management resource in seasonal agricultural-worker programs

SARA MARIA LARA FLORES

11 Stranded migrants, mobile subjects: the spatiality and social order of 'waiting' in Mexico LAURENT FARET

12 Facing the environmental transition: the critical issue of grasping mobile spatialities at the crossroads of (un)changing practices and policies JEAN-BAPTISTE FRÉTIGNY AND JULIETTE MAULAT

13 Work and high mobility: current knowledge and blind spots EMMANUEL RAVALET AND YANN DUBOIS

Afterword: hybridities, transgressions, and stranded mobilities MIMI SHELLER 


\title{
4 Clouds and movements
}

\author{
Panos Bourlessas and Alberto Vanolo
}

\subsection{Different kinds of clouds}

In the early twentieth century, E.J. Marey, a French physiologist, doctor, biomechanics engineer, and the inventor of chronophotography, attempted the then-unthinkable documentation of the movements of air. To achieve this, he had to produce something that would make invisible airflow movements visible. And so, he produced clouds. These were generated by tube machines in which trails of smoke encountered objects of various shapes, thus becoming visible traces of a never-ending movement. ${ }^{1}$ Indeed, in E.J. Marey's photographic images of his experiments, clouds themselves are movement: they are the matter of movement captured momentarily in space and time by the camera lens. From science to the arts - with E.J. Marey's work transgressing the boundaries between them-clouds have fascinated people throughout history. In both science and the arts, clouds are archetypical elements of movement; they are elements with an inherent ephemerality and mutability in both nature and culture. They refer to an endless movement that needs to be understood, categorized, mastered, controlled, represented, imagined-and eventually invented (Hamblyn 2002).

Over the years, geographers have diverted their epistemological gaze, looking at the various spatial relationships that shape our natures and cultures above the ground, yet which are not the earthy, solid materialities that geography, both human and physical, has traditionally focused on. This has entailed considering previously overlooked elements, such as water and air, as being pivotal to the shaping of an understanding of space that is processual,

1 The machine used by E.J. Marey is described here: Machine à fumée, soufflerie aérodynamique, Catalogue des Appareils Cinématographiques de la Cinémathèque Française et du CNC, last viewed on 15 December 2020, www.cinematheque.fr/fr/catalogues/appareils/collection/ machine-a-fumee-soufflerie-aerodynamiqueap-18-3274.html.

An example of photo is available at: Marey, E.J. 1901, Prisme triangulaire présentant au courant une de ses bases, quatrième et dernière version de la machine à fumée, équipée de 57 canaux, Musée d'Orsay, Paris, last viewed on 15 December 2020, www.musee-orsay.fr/fr/ evenements/expositions/archives/presentation-detaillee.html?zoom=1\&tx_damzoom_pi1\%5B showUid\%5D=100376\&cHash=2da8e4b58b. See also: F. Dagognet 1992.

DOI: $10.4324 / 9781003023562-5$ 
non-static and made of non-terrestrial components and practices (Peters, Steinberg \& Stratford 2018).

This chapter presents some theoretical speculations related to debates on post-human geographies and atmospheric geographies in order to develop analyses of movement. Specifically, it mobilizes different understandings of clouds as an attempt to challenge conventional dichotomies, such as the human and the non-human, nature and culture, mobility and stasis, science and fiction. Such reflections build on long-standing problematizations regarding the divide between human and physical geography (Massey 1999), as well as more recent calls to bridge traditional schisms in the discipline by seeking a 'unified geography' (Sui \& DeLyser 2012, p. 2). We argue here that the cloud as a post-human element can exemplify how such a unified geography can be achieved, through the multiple movements to which the cloud can relate.

Taking inspiration from P. Merriman and L. Pearce (2017) and their reflections on 'mobility and the humanities', the speculative exercise proposed in this chapter will focus on clouds and their movements. It is rather evident that the word 'cloud' means different things to different audiences and thus relates to respectively different discourses. This chapter focuses on three parallel discourses, each one characterized by the different perspectives, languages, logics, ideologies, and aesthetics of clouds; each one dictates, either implicitly or explicitly, a different way of understanding and framing movement. Ideally, the three sections, focusing on the three parallel discourses, can be read in any order, as they constitute independent vignettes.

The first discourse, presented in the next section, focuses on clouds as gasses, and it refers to the kind of knowledge on clouds provided by atmospheric physics, astronomy, meteorology, and physical geography. The section mobilizes a technical language describing the behavior and movement of molecules and gasses, and the ways clouds - from ordinary clouds observable in the sky, to interstellar clouds that are beyond direct observation-have been studied and classified according to their ever-changing shapes, compositions, origins, and movements.

The second discourse focuses on the cultural understandings of clouds and their movement. Here, the language and the perspectives are closer to the arts and humanities: the cloud is not intended as a 'natural' object that pre-exists humans, but rather as a cultural object whose meanings are socially and culturally constructed. Put differently, the literal and metaphorical movement of clouds is inherent to cultural understandings of these post-human elements, from phenomenological perceptions to artistic works.

The cloud in computer science is at the center of the third discourse. Here, the cloud exists in relation to grid computing, distributed scientific data, codes, and platforms. The language is again technical, but partially different from the one used in atmospheric physics. Cloud computing, in fact, is hardly observable in physical form, beyond the materiality of computers, servers, and cables (Kinsley 2014), and the idea of the cloud as a place to which one 
moves and accesses data and computational functions is, to a large degree, metaphorical and evocative. It mobilizes perspectives and languages that, in many cases, echo those proposed in relation to clouds in cultural and artistic representations.

By mobilizing these three parallel discourses on clouds, this chapter builds on (and aims to contribute to) different and overlapping literatures, mainly along two lines.

First, the analysis draws on post-humanist geographies that aim to decenter the human subject as distinct from other forms of life: i.e., these geographies acknowledge the relevance of non-human agents and subjects (Castree \& Nash 2006; Wright et al. 2020). The three discourses on clouds proposed here challenge conventional binaries opposing nature and culture as static entities. Instead, they emphasize the flexibility and erosion of the two categories, with cloud computing being one of the most explicit examples as its hybridization of the human and non-human (machine) transgresses human forms of perception (Amoore 2018). Such a line of reflection also builds on contributions from the philosophy of science, such as those of I. Stengers (2003), who investigated the paradoxical mode of existence of elements transgressing the timeframe of human knowledge, so that they simultaneously 'exist' and are constructed by physics 'for us' (Amoore 2018; Wright et al. 2020).

Second, this chapter can be situated in the field of aerial and atmospheric geographies. According to these literatures, air 'is a contrived concept tied to various scientific, managerial, and geo-discursive interventions that render its properties imaginable and spatially manipulable' (Lin 2018, p. 36). Through the elements that it embraces and activates, air is where the human body relates to the world, where such relations are constantly subject to disturbances, and where various forms of aerial mobility and subjectification are practiced (Adey 2010; Martin 2011; Lin 2018). Specifically, in concert with developments on affect, the new materialisms, and non-representational theories, various transdisciplinary contributions have analyzed how atmospheres-including meteorological ones - influence bodies, technologies, images, and discourses (McCormack 2013), and arguably conceptualizations of movement.

With this aim in mind, the next sections will focus on understandings of clouds as gasses, cultural objects, and data respectively. The final section will then provide some general reflections on the various forms of geographical knowledge and movement.

\subsection{Clouds / gasses}

According to the World Meteorological Organization:

A cloud is a hydrometeor consisting of minute particles of liquid water or ice, or of both, suspended in the free air and usually not touching the ground. It may also include larger particles of liquid water or ice as well 
as non-aqueous liquid or solid particles such as those present in fumes, smoke or dust.

(WMO 1975, p. 9)

Water vapor is a gas with peculiar features (Wang 2013). First of alland differently from other gasses that abound in the atmosphere $-\mathrm{H}_{2} \mathrm{O}$ concentrations vary consistently from place to place: the highest values (about $4 \%$ are found above the Indian Ocean, while clouds are virtually absent over deserts. Second, water vapor is mostly present in the lowest strata of the atmosphere, decreasing with height. A further layer of complexity is added by the fact that water vapor has the unique character of evaporating and condensing in both liquid and solid form (i.e., as water droplets and ice particles) in the conditions of temperature and pressure present in the troposphere. Transitions between phases typically involve large amounts of energy transferred as latent heats, which have an impact on weather processes. The moisture in the atmosphere, the horizontal and vertical distribution of clouds, and their movement all influence weather, precipitation, and the radiation budget of the planet, and they all play a key role in climate studies. The very shape of the planet - mountains, valleys, rivers, and deserts - and the composition of the atmosphere (i.e., the dissolving of most of the water-soluble gasses that abounded in the ancient atmosphere) are also related to clouds and precipitation. Clouds are also present on other planets, such as Venus and Mars, but they do not produce rain there.

Water vapor is basically located in the troposphere and ordinary clouds are absent in the stratosphere. Still, it is possible to observe other kinds of clouds there, mostly made of sulfuric- or nitric-acid aerosol particles characterized by brilliant, iridescent colors due to diffraction phenomena. This is quite common in the polar regions. At a higher level, in the mesosphere (at an approximate altitude of $76-85 \mathrm{~km}$ ), particularly at latitudes between $50^{\circ}$ and $70^{\circ}$ north and south of the equator, it is possible to observe noctilucent clouds during the summer. These are the highest clouds present in earth's atmosphere, and they are made of ice crystals (Lutgens \& Tarbuck 2016).

Outside the earth's atmosphere, there are interstellar clouds, which have nothing to do with meteorological phenomena. They are made of interstellar matter, consisting mostly of gas and dust particles composed of silicate and carbonaceous compounds, with sizes typically around $0.1 \mu \mathrm{m}$ in diameter (Yamamoto 2017). Stars are formed out of such clouds. More precisely, they are formed when interstellar gas clouds of sufficient mass collapse under their gravitational pull (LeBlanc 2010). Depending on the cloud's characteristics in terms of density, size, and temperature, their hydrogen content can be neutral (known as a H I region), ionized (H II region), or molecular. The chemical composition of interstellar clouds can be identified by the electromagnetic radiation they emanate, which can be analyzed using radio telescopes (Wilson et al. 2013). Interstellar clouds may be classified in various ways, including in terms of their velocity. High-velocity interstellar clouds (HVCs) have a 
velocity higher than can be explained by the rotation of the Milky Way, and a number of hypotheses have been put forward to explain their origins and movement (see for example the classical articles by Spitzer \& Schwarzschild 1951, 1953).

While interstellar clouds are detected using radio telescopes, atmospheric clouds are mainly analyzed and classified by mobilizing two approaches: direct observation and satellite data. Classifications based on direct observations still draw largely on a study published in 1803 by Luke Howard, a British chemist with a love of meteorology (Pedgley 2003). His classification strongly echoes Linnaean principles of classification applied to flora and fauna, which is based on genres, species, and varieties. Today, the World Meteorological Organization (WMO) proposes a classification with ten mutually exclusive categories, and a number of species (a cloud may belong to just one species) and varieties (a cloud may belong to multiple varieties). In addition, clouds are classified according to other supplementary features, as well as by the presence of accessory clouds (sometimes merged with the main body) and by mother-clouds, as clouds may also form or grow from other clouds designated as such (see Table 4.1).

Each genre is based on specific characteristics related to parameters such as height and luminescence. For example, the genre 'cirrocumulus' is defined as a:

Thin, white patch, sheet or layer of cloud without shading, composed of very small elements in the form of grains, ripples, etc., merged or separate, and more or less regularly arranged; most of the elements have an apparent width of less than one degree.

(WMO 1975, p. 16)

Species are based on observed peculiarities in the shape and differences in their internal structure. For example, the uncinus species is described as 'shaped like a comma, terminating at the top in a hook, or in a tuft the upper part of which is not in the form of a rounded protuberance' (WMO 1975, p. 18). There are several specific techniques for the direct, ground observation of clouds, and the WMO provides very detailed and codified standards in terms of the observer's position, the description of clouds, as well as the codes and symbols for the classification. The movement of clouds is based on the estimation of their speed from a specific standpoint, using a visual element in the horizon as a landmark, or by estimating the speed of the shadow of a cloud on the ground.

By contrast, satellite data are characterized by an observation position that is located above the earth, and data are generated by sensors (Kidder \& Vonder Haar 1995; for a review of the evolution of methodologies and technologies see Harper 2008; Kidd, Levizzani \& Bauer 2009). Satellite classification is based on seven 'cloud types', and it is different from the one proposed by the WMO in relation to direct observation. Traditionally, satellites scrutinized clouds by using visible and infrared imageries. However, today, 
Table 4.1 The classification of clouds according to the World Meteorological Organization

\begin{tabular}{|c|c|c|c|c|}
\hline \multicolumn{3}{|c|}{ GENERA } & \multicolumn{2}{|c|}{ SPECIES } \\
\hline Designations & Abbreviations & Symbols & Designations & Abbreviations \\
\hline Cirrus & $\mathrm{Ci}$ & $\rightarrow$ & fibratus & fib \\
\hline Cirrocumulus & $\mathrm{Cc}$ & $>$ & $\begin{array}{l}\text { uncinus } \\
\text { spissatus }\end{array}$ & $\begin{array}{l}\text { unc } \\
\text { spi }\end{array}$ \\
\hline Cirrostratus & Cs & $\angle$ & castellanus & cas \\
\hline Altocumulus & Ac & $\cup$ & $\begin{array}{l}\text { Floccus } \\
\text { stratiformis }\end{array}$ & $\begin{array}{l}\text { flo } \\
\text { str }\end{array}$ \\
\hline Altostratus & As & $\angle$ & nebulosus & neb \\
\hline Nimbostratus & Ns & 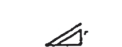 & lenticularis & len \\
\hline Stratocumulus & $S_{c}$ & $\approx$ & humillis & hum \\
\hline Stiator titutus & $\mathrm{sc}$ & 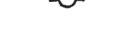 & mediocris & med \\
\hline Stratus & St & -- & congestus & con \\
\hline Cumulus & $\mathrm{Cu}$ & $R$ & $\begin{array}{l}\text { calvus } \\
\text { capillatus }\end{array}$ & $\begin{array}{l}\text { cal } \\
\text { cap }\end{array}$ \\
\hline Cumulonimbus & $\mathrm{Cb}$ & 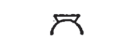 & & \\
\hline \multicolumn{3}{|c|}{ VARIETIES } & \multicolumn{2}{|c|}{$\begin{array}{c}\text { SUPPLEMENTARY FEATURES } \\
\text { AND ACCESSORY CLOUDS }\end{array}$} \\
\hline Designations & \multicolumn{2}{|c|}{ Abbreviations } & Designations & Abbreviations \\
\hline $\begin{array}{l}\text { intortus } \\
\text { vertebratus } \\
\text { undulatus } \\
\text { radiatus } \\
\text { lacunosus } \\
\text { duplicatus } \\
\text { translucidus } \\
\text { perlucidus } \\
\text { opacus }\end{array}$ & \multicolumn{2}{|l|}{$\begin{array}{l}\text { in } \\
\text { ve } \\
\text { un } \\
\text { ra } \\
\text { la } \\
\text { du } \\
\text { tr } \\
\text { pe } \\
\text { op }\end{array}$} & $\begin{array}{l}\text { incus } \\
\text { mamma } \\
\text { virga } \\
\text { praecipitatio } \\
\text { arcus } \\
\text { tuba } \\
\text { pileus } \\
\text { velum } \\
\text { pannus }\end{array}$ & $\begin{array}{l}\text { inc } \\
\text { mam } \\
\text { vir } \\
\text { pra } \\
\text { arc } \\
\text { tub } \\
\text { pil } \\
\text { vel } \\
\text { pan }\end{array}$ \\
\hline
\end{tabular}

M O T H E R-C L O U D S

GENITUS

MUTATUS

\begin{tabular}{l|l|l|l}
\hline \multicolumn{1}{c|}{ Designations } & \multicolumn{1}{|c|}{ Abbreviations } & \multicolumn{1}{c}{ Designations } & \multicolumn{1}{c}{ Abbreviations } \\
\hline cirrocumulogenitus & ccgen & cirromutatus & cimut \\
altocumulogenitus & acgen & $\begin{array}{l}\text { cirrocumulomutatus } \\
\text { cirrostratomutatus }\end{array}$ & csmut \\
altostratogenitus & asgen & altocumulomutatus & acmut \\
nimbostratogenitus & nsgen & altostratomutatus & asmut \\
stratocumulogenitus & scgen & nimbostratomutatus & nsmut \\
cumulogenitus & cugen & stratocumulomutatus & scmut \\
cumulonimbogenitus & cbgen & stratomutatus & stmut \\
& & cumulomutatus & \\
\hline
\end{tabular}

Source: WMO (1975, p. 13). 
satellite images are automatically processed, and it is possible to represent the movement of clouds by collecting sequences of images, as found in the typical aesthetic repertoire of weather forecast news.

Clouds are produced out of the mobility of air flows, and there are basically four different genealogies (Lutgens \& Tarbuck 2016). Orographic lifting occurs when winds push air over an obstacle, such as a mountain. The air, rising to pass the obstacle, gets cooler, and hence vapor condenses. Frontal lifting happens when a mass of cold air pushes under (a cold front) or slides over (a warm front) warmer air. Clouds form as the warm air cools. Convergence occurs as two air flows meet and interact, causing an accumulation of mass that eventually leads to a vertical movement and to the formation of clouds and precipitation. Finally, convective lifting relates to the unequal heating of the earth's surface, causing pockets of air to be warmed more than the surrounding air.

\subsection{Clouds / cultures}

As essential ingredients of the 'weather-world', clouds are primal elements of bodily perception. According to T. Ingold (2007, 2008, 2010), the weatherworld consists of the ever-moving natural fluxes that take place above the solidity of the ground: it is the medium in which human and non-human life is immersed. In fact, the weather-world, together with the direct, embodied, sensory perception of it, is that which makes people inhabitants, and not exhabitants, of the world. In all this, clouds are not static objects that simply furnish the sky. Instead, each cloud is 'an incoherent, vaporous tumescence that swells and is carried along in the currents of the medium' (Ingold 2008, p. 6). In this medium (the air), people engage with clouds in a bodily manner, such as feeling the change in temperature when a cloud moves in front of the sun or when it pours rain on us. Yet, although we experience such fully embodied engagement, our visual perception of clouds is the primary way in which we relate to them.

We can experience fog by being immersed bodily in it, and this disturbs our vision and perception of place (Martin 2011; Frers 2013). Clouds, however, are like moving surfaces in the air, and they are mostly seen from a distance: we are barely ever immersed in clouds and, when this happens, it is mainly not directly but instead is mediated by, say, an aircraft's cabin and by technologies while flying. In his book The Ecological Approach to Visual Perception, J.J. Gibson (2015) includes clouds among those characteristic textures of surfaces found in nature. Like all other textures, such as grass and wood grain, they can be seen and hence identified as such. Yet, unlike all others, the texture of clouds cannot be touched. For the clouds' moving surface exists only at a distance and through our gaze. Clouds' substance consists of an aerial materiality that is not tactile - the 'immaterial materiality' that is so characteristic of gasses and their infinite movement. Therefore, in response to Jacobus' statement that clouds 'combine visibility and volume 
without surface' (2006, p. 219, emphasis added), we would say that clouds are surfaces. Yet these surfaces only exist through visual perception; they are surfaces touched with the eyes only, something exemplified in R. Magritte's 1928 painting The False Mirror. ${ }^{2}$

These considerations allow us to speculate on the centrality of the visual realm, as it is through our gaze that clouds become spatialized in culture. First, they can be conceived of as boundaries. For the ancient Greeks, the clouds divided the air into two regions: 'the realm of brightness above the clouds', known as the aether, and 'the dim, moist atmosphere below them', known as aer (Connor 2010, p. 15). At the same time, despite their ethereal texture perceived only visually, clouds seem to be concrete enough to become actual terrains of the imagination; where gods and goddesses reside, where dreams take place, where our beloved ones move to when they pass away. In their ephemerality, clouds construct an imagined juxtaposition between the real and the imagined, the natural and the supernatural, and the (down here) impossible and the (up there) possible. If air, as P. Adey (2014) suggests, is the site not only of respiration but also of aspiration, then clouds as spatialities may be considered the 'ethereal ground' of aspiration.

It is no surprise that clouds and cloud mobilities have inspired many artistic works, including those mentioned earlier in this chapter. Putting forward the concept of the poetics of air, S. Engelmann (2015) suggests an engagement with an art installation aimed at attending to air and the atmosphere in affective and aesthetic ways, as well as introducing novel geographic concerns that, in our view, relate to the new ontologies pursued here. With this aim in mind, we will engage with a poetics of clouds, with the help of a work of art by Berndnaut Smilde entitled Nimbus. Basically, the artist creates elements of a cloud within a closed space, physical and visually, and he documents the result. He sprays water in the atmosphere so that the air becomes moist. Then, a machine produces smoke. The droplets of water that stick on the smoke make it heavier and thus slow down its movement. A spotlight illuminates the smoke from behind, and before the smoke dissolves totally after a few seconds, Berndnaut Smilde photographs the scene (see Image 4.1).

At the level of artistic practice, Berndnaut Smilde uses knowledge, technical means as well as physical ingredients, such as water, to reproduce the materiality of clouds for his purposes. However, although this process is technically and technologically orchestrated, and while the indoor space in which it unfolds is controlled, there is something that escapes the artist's power, namely the cloud's mobility. Indeed, from its first appearance in the room's moist air until it dissolves fully a few seconds later, the cloud does not stop moving. The droplets sprayed in the air by Berndnaut Smilde only slow down the movement; they do not prevent it. As long as it moves throughout the

2 Magritte, R. 1929, The False Mirror, Oil on canvas, 54 x $80.9 \mathrm{~cm}$, MoMa, New York, last viewed on 15 December 2020, www.moma.org/collection/works/78938. 


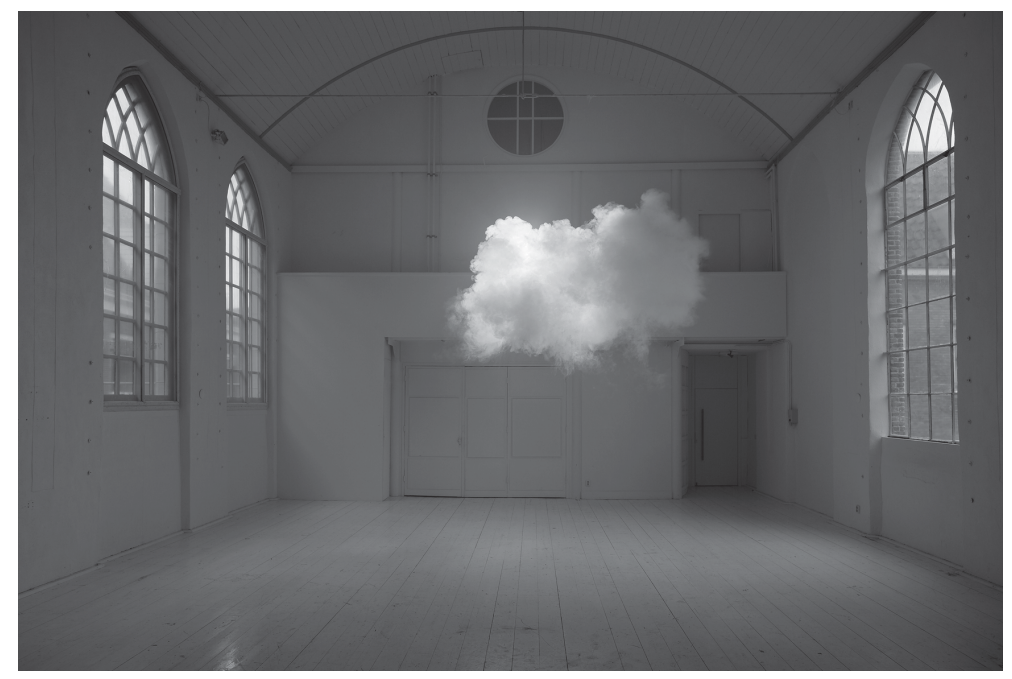

Image 4.1 Nimbus II, by Berndnaut Smilde (2012). Source: Cassander Eeftinck Schattenkerk.

room, the cloud is visually perceived and can be captured as a cloud. In other words, the cloud does not exist outside of its endless movement. It is movement, not the cloud per se, that becomes the artwork: "the work is the documentation', as Berndnaut Smilde comments on Nimbus (personal communication, 15 October 2018). Therefore, what is documented in the pictures is the unstoppable and thus ungraspable movement of the cloud. The movement of something - the cloud that was there - that is, as a result of this very movement, no longer there. It is only by capturing the movement photographically that the artist finally captures the cloud itself.

At a second, representational level, Nimbus achieves a certain conceptual movement: the cloud as a non-human element moves from being outdoors, where it 'naturally' belongs, to being indoors, from where it is supposed to be kept out. The cloud moves from the uncontrolled, unpredictable, everchanging weather-world to the human-made, structured, appropriated interior-world. The result of this conceptual movement is the domestication of the cloud; nature is thus physically brought into culture and the latter's physical spatialities. In the artwork's nature-culture visual entanglement, the mobility inherent to clouds is emphasized. The Nimbus cloud is no longer a distant element in the air; rather, it inhabits the very spaces that wehumans - inhabit. Yet, together with the cloud, movement inevitably also inhabits these places, as the two cannot be perceived separately. Herein lies a multiple contrast that is so essential to Berndnaut Smilde's work and so central to understanding the cultural aspects of cloud mobilities: the contrast 
between the endless movement of the cloud and the seeming stillness of built space.

Specifically, we suggest that the contrast unfolds gradually through three interrelated levels that concern the mobility of clouds, beyond Berndnaut Smilde's artistic work: those of materiality, form, and temporality. First, at the level of materiality, the solidity and tactility of the built environment, such as the room in the artistic experiment, contrasts with the clouds' ethereality and non-tactility; the former's materiality is static whereas the latter's is floating and unstable. Second, and deriving from materiality, at the level of form the linear and pre-given order of human artifacts - in this case the room's space - contrasts with the non-linear and unpredictable (due to its constant movement) form of the cloud. The latter thus challenges the 'phenomenology of the visible' in Cartesian terms (Jacobus 2006, p. 221). Third and last, at the level of temporality, the solid built form of many human artifacts, such as the room, represents a resistance to the passage of time: a resistance of (the) stillness (of matter) against (the) movement (of time); the decaying walls in some of the Nimbus images emphasize this exactly. In contrast, the domesticated cloud follows the movement of time instead of resisting it. Because of the movement inherent in its existence, every cloud is temporary; as long as it moves it is there, visible; but the end of its movement marks the end of its materiality, as clearly happens in Berndnaut Smilde's artistic work. After time has passed and the cloud's materiality has dissolved, what remains is an empty, solid, linear space with some sort of historicity, in which one can gaze upon just one thing: stillness.

\subsection{Clouds / data}

Cloud computing is currently a well-known buzzword in technology. According to V.V. Arutyunov (2012), it is basically a synonym for 'diffused' computing or data processing. This refers to a technological architecture wherein computer resources and capacity are provided to the user as internet services. Users may access data without caring about the core elements of the digital (and material) infrastructure, the operating system, and software they work with. Information is stored on internet servers, and it is cached temporarily on client platforms, such as desktop computers, notebooks, hand-held devices, sensors, game consoles, and monitors. This information storage is made possible by what are known as virtualization technologies, which allow the separation of a physical computing device from multiple 'virtual' devices (Armbrust et al. 2010). The idea of 'storing' information on an online server, or accessing data and computational capabilities from the cloud, basically entails the capability of moving information, pursuing the quest for absolute data mobility that is apparently free of any infrastructural constraint.

Cloud computing offers radically new possibilities for the IT industry, and it has pushed toward a major reshaping of how hardware and software are designed, purchased, and consumed, including new possibilities 
for value extraction and labor exploitation (Srnicek 2017; Oppitz \& Tomsu 2018). According to enthusiasts, developers of internet services no longer require large capital or technological skills in order to operate on the market. Moreover, they do not need accurate predictions for supply, as it can be cheaply and quickly scaled up or down, providing more or less server capacity in order to deal with growing or diminishing customer use. Economies of scale do not seem to matter anymore in this economic sector, allowing for a complete reshaping of the political economy of information technologies, which shapes new possibilities for creative ideas and start-ups. Expressions such as 'software as a service' (SaaS), 'infrastructure as a service' (IaaS), 'workplace as a service' (WaaS) or 'platform as a service' (PaaS) refer to such transformations.

The genealogy of the concept of cloud computing, and specifically the story of how the cloud has been mobilized as a metaphor, is unclear and controversial. Some observers date the birth of the term to 25 August 2006, when Amazon announced a limited public beta test of the Amazon Elastic Compute Cloud, allowing users to rent virtual computers on which to run their own computer applications. Two years later, cloud computing services were famously proposed by Google through its Google App Engine; in the same year Microsoft announced its cloud computing service named Azure, and Dell tried to copyright the term. However, various authors have detected relevant precedents in the development of the idea of cloud computing.

The idea of sharing resources through computing networks and thinking of computational activities as services dates back to the 1960s: as early as in 1961, Professor John McCarthy proclaimed at MIT that computing may someday be organized as a public utility, just as the telephone system is a public utility (quoted in Garfinkel 2011). And, indeed, attempts were made to develop remote job technologies during the 1960s. However, references to clouds only took form many years later. In particular, during the 1990s virtual private networks (VPNs) became popular, and they started to be visually represented on computers with the symbol of a cloud. According to S. Mattern (2017, p. xix), who uses approaches from media archaeology, the cloud is one example of a 'conceptual mold' giving rise to a discursive pattern that helps us to imagine media, technologies, and their place in the world.

For A. Regalado (2011), the first explicit use of the expression 'cloud computing' dates back to 1996, in the offices of Compaq Computer. A small group of technology experts developed a detailed and prophetic vision of the future of the internet, including the diffusion of cloud-computingenabled applications like consumer file storage, video conferences, and the streaming of sports events. In May 1997, a trademark application for 'cloud computing' was presented by a now-defunct company called NetCentric that was in business with Compaq, but the request was never approved (Regalado 2011). Both a Compaq executive and the NetCentric manager claim the paternity of the term 'cloud computing', and they both agree that it was born as a marketing term. At the time, telecom networks were already referred to 
and visually represented as clouds. They were simply searching for a slogan evoking the potential of fast-developing internet opportunities. However, the slogan did not become popular at that time, and Compaq dropped it. Most probably, other experts independently coined the term at a later date.

Given the metaphorical use of the term 'cloud', and given the current hype concerning cloud technologies and related businesses, it is no surprise that the term remains very ambiguous and difficult to define (Armbrust et al. 2010; Regalado 2011; Arutyunov 2012). According to a CEO of Oracle:

The interesting thing about cloud computing is that we've redefined cloud computing to include everything that we already do. ... I don't understand what we would do differently in the light of cloud computing other than change the wording of some of our ads.

(Armbrust et al. 2010, p. 50)

Put differently, the technologies and the imaginaries behind cloud computing precede the current discursive construction of cloud computing, which has developed in recent years and is still unfolding.

To give an idea of the heterogeneity of computer clouds, it is worth mentioning the fact that a number of classifications are put forward in the literature. This means that there is a science of observing and classifying clouds, as in the case of information technologies. According to J.D. Peters (2015), the mobility of the term across environmental discourses and media studies reveals that the two spheres are not at all separated, but rather hybrid: we can think of media as environments and also think of environments as media.

The simplest classifications identify some idea-typical forms of clouds. V.V. Arutyunov (2012), for example, focuses on the end-users' side by distinguishing between private clouds (operated solely for an organization), community clouds, public clouds (designed for free use by a wide public), and hybrid clouds (merging two or more different kinds of clouds). Other authors distinguish between cloud computing and other similar forms of clouding, such as 'fog computing' (a specific architecture privileging edge devices) and a 'cloud sandbox' (an isolated networked environment for testing software). C.S. Höfer \& G. Karagiannis (2011) propose a classification tree with multiple hierarchical ramifications by combining different taxonomies regarding the nature of the services, common characteristics of the clouds, and specific technical aspects of the services. This tree ultimately allows the identification of hundreds of possible clouds (see Figure 4.1).

It is interesting to notice that computing clouds are, to a large degree, invisible entities. Of course, Wi-Fi networks, cloud storage, and phone connections are based on material infrastructures of very significant geographical dimensions, but a large part of clouds' infrastructures remain immaterial and invisible to the average user. At the same time, artists and designers have produced a number of maps, apps, soundwalks, and installations aimed at making those networks visible, as for example in the case of Richard Vijgen's 


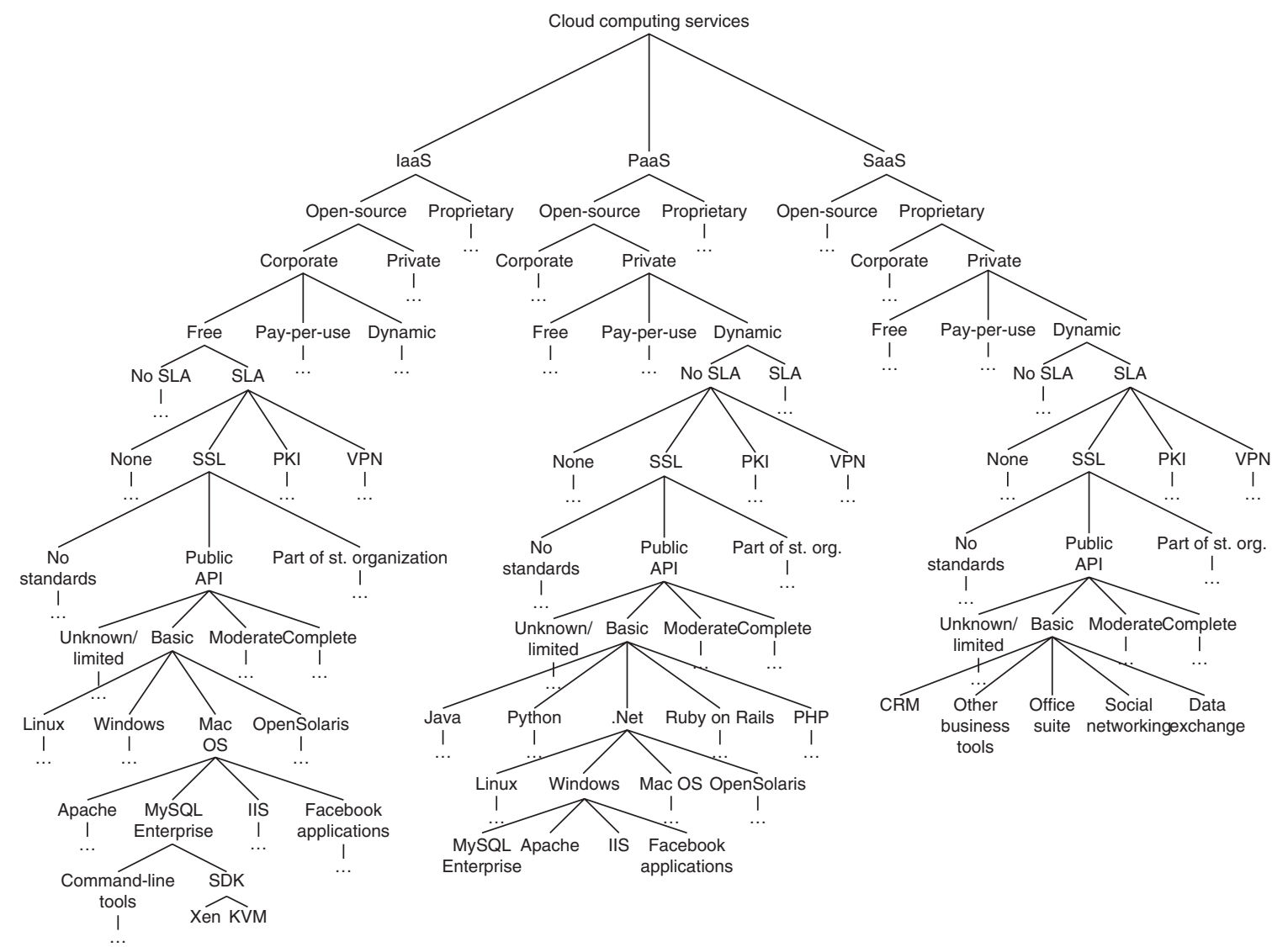

Figure 4.1 A classification tree for computer clouding. Source: Höfer \& Karagiannis (2011, p. 89). 
Architecture of Radio app, developed in 2005, which transformed signals from Wi-Fi routers, satellites, cell-phone towers and fixed cabling into images and sounds (Maddern 2017).

The ultimate result of artistic experiments in the visualization of clouds and related data mobilities confirms a thesis proposed by S. McDowell et al. (2008), more than a decade ago, in their development of the concept of infosphere, intended as a 'metaphor of an image, an ever-shifting space, constructed and continually reconstructed for and by the movement of information' (p. 11). According to the authors, the infosphere is a space of governance, technology, and cultural practice in motion, where motion refers both to the dynamism of the very concept, and to the specific role of the infosphere as a space of movement implying data replication, connectivity, and infrastructures. The metaphorical nature of our understanding of clouds is clear, for example, in our conventional understanding of data mobility, as data do not really move from one position to another, but rather data are duplicated in another location. The imaginary of the infosphere as a transparent, nebulous cloud, as frequently represented in network diagrams, can therefore hamper the construction of theory. On the one hand, the infosphere possesses a geography consisting (in part) of corridors and boundaries of interaction, shaped to a large degree by material and tangible forms of politics, power, and governance. On the other hand, completely new understandings of geography and mobility are needed in order to capture the nature of data mobility and to develop further our understanding and our consciousness of digital clouds.

\subsection{Concluding remarks}

This chapter has proposed three possible parallel discourses of clouds and their movement, focusing on clouds as gasses, cultures, and data. These three perceptions of clouds of course do not cover the entire spectrum of possible meanings and discourses concerning clouds and their movements, and the limited length of this chapter does not allow us to engage with detailed and sophisticated analyses within the three different discourses and their related fields of knowledge (for a wider discussion, see Hamblyn 2017). Indeed, many of the concepts and scientific facts presented in the previous pages are probably already known to the reader, in some implicit or explicit ways. Yet, the purpose of presenting them is precisely to emphasize their different styles and epistemological perspectives. Put simply, the three discourses look quite different from each other, as they approach and treat clouds in different ways, they mobilize diverse languages, and they seem to relate to different spheres of knowledge and to different audiences. Still, there are recurring elements: for example, both the first and the third discourse insist on classification exercises based mainly on typologies and categories, with a strong emphasis on morphological criteria. The 'aesthetics of knowledge' of Figure 4.1 and Table 4.1 are hence quite similar, insisting on hierarchical order, fixed categories, and labels. It suggests a centrality of classification in our mechanism of knowledge 
production (Bowker \& Star 2000), and this is quite striking if one considers that one of the key features of clouds is their relative lack of stable form and place, transforming constantly and being in a state of becoming and in movement. In other words, in order to classify and to build typologies, cloud movements have had somehow to be tamed by defining fixed and generalizable categories.

Furthermore, all the three discourses allow for observations of how our understandings and representations of clouds have changed over time according to technological and cultural movements. For example, satellite observations have allowed new classifications of clouds, as these observations have moved the boundary between the observable and the unobservable. Artistic practices make data flows visible that are otherwise impossible to detect visually. Clouds are also made and unmade through discursive and representational practices: the genealogy of cloud computing presented in the previous section basically describes the becoming of clouds. It does so in a way that reveals parallels with the materiality of the making of clouds proposed by the artist Berndnaut Smilde in a different section, or with the genealogy of the science of the classification of atmospheric clouds described in Figure 4.1.

Our decision to put these three discourses together in one chapter is clearly a strategy that aims to transgress and cut across epistemological boundaries in human geography, with relevant implications for debates on mobilities. As stressed by M. Ward (2014) in the sphere of cultural geography, it is possible to conceptualize the spatialities and performances of an academic text. Here, a strategy of geographical transgression has been tentatively enacted by locating the three (apparently) disconnected discourses within the same chapter. The clouds that have been moving throughout textual space have also been moving through the broader epistemological space of geography, which hosts different types of knowledge, languages, and themes: technicaldescriptive, cultural-artistic, and computational-technological.

Such a textual performance echoes recent trends in mobility studies, and particularly the need to bridge contributions from the arts and humanities, on the one hand, and social sciences, on the other hand, as recently discussed by P. Merriman and L. Pearce (2017). Therefore, this chapter aims to respond to this call by reflecting on the different kinds of movement enacted by, through, within, and in relation to clouds. Different perspectives, discourses, meanings, and ways of observing clouds allow for potentially different ways of conceiving rhythms, temporalities, scales, and spatialities. More specifically, P. Merriman and L. Pearce (2017) argue that scientific discourses tend to assume that space, time, distance, speed, and acceleration do all have a clear functional relationship, and that the experiences and meanings of and around movement are simply 'external' to the physical word. By merging contributions from cultural geography and from the science of physics - that is, by transgressing conventional epistemological and discursive boundaries - this chapter aims to suggest the presence of a multitude of spatialities and temporalities associated with 
the movement of non-human and more-than-human objects. For putting a non-human, 'natural' element in movement throughout a textual and consequently broader epistemological space, such as that of cultural geography and technology studies, we seek to unveil only some of the transgressive possibilities of an ethereal element that might point to new geographic ontologies. In this sense, the chapter highlights the crucial tension between the need for building fixed categories, on the one hand, and the difficulty of conceptualizing objects that do not have fixed and well-defined boundaries or stable geographical locations, such as the various kinds of clouds considered here. Overall, our examination suggests the need for geography to look at movement as an ontological category that may require forms of knowledge that go beyond perspectives focusing on presence, form, analogy, and classification.

\section{References}

Adey, P. 2010, Aerial life. Spaces, Mobilities, Affects, Wiley-Blackwell, West Sussex. 2014, Air: Nature and Culture, Reaktion, London.

Amoore, L. 2018, 'Cloud Geographies: Computing, Data, Sovereignty', Progress in Human Geography, vol. 42, no. 1, pp. 4-24, DOI: 10.1177/0309132516662147.

Armbrust, M., Fox, A., Griffith, R., Joseph, A. D., Katz, R., Konwinski, A., Lee, L., Patterson, D., Rabkin, A., Stoica, I. \& Zaharia, M. 2010, 'A View of Cloud Computing', Communications of the ACM, vol. 53, no. 4, pp. 50-58, DOI: 10.1145 / 1721654.1721672.

Bowker, G.C. \& Star, S.L. 2000, Sorting Things Out: Classification and its Consequences, MIT Press, Cambridge.

Castree, N. \& Nash, C. 2006, 'Posthuman Geographies', Social \& Cultural Geography, vol. 7, no. 4, pp. 501-504, DOI: 10.1080/14649360600825620.

Connor, S. 2010, The Matter of Air. Science and the Art of the Ethereal, Reaktion, London.

Dagognet, F. 1992, Etienne-Jules Marey: Passion for the Trace, Zone Books, New York.

Engelmann, S. 2015, 'Toward a Poetics of Air: Sequencing and Surfacing Breath', Transactions of the Institute of British Geographers, vol. 40, no. 3, pp. 430-444, DOI: $10.1111 /$ tran.12084.

Frers, L. 2013, 'The Matter of Absence', Cultural Geographies, vol. 20, no. 4, pp. 431445, DOI: $10.1177 / 1474474013477775$.

Garfinkel, S. 2011, 'The Cloud Imperative', MIT Technological Review, last viewed on 16 December 2020, www.technologyreview.com/s/425623/the-cloud-imperative.

Gibson, J.J. 2015, The Ecological Approach to Visual Perception, Psychology Press, New York.

Hamblyn, R. 2002, The Invention of Clouds. How an Amateur Meteorologist Forged the Language of the Skies, Picador, London.

2017, Clouds, Reaktion, London.

Harper, K.C. 2008, Weather by the Numbers: the Genesis of Modern Meteorology, The MIT Press, Cambridge.

Höfer, C.S. \& Karagiannis, G. 2011, 'Cloud Computing Services: Taxonomy and Comparison', Journal of Internet Services and Applications, vol. 2, no. 2, pp. 81-94, DOI: $10.1007 / \mathrm{s} 13174-011-0027-x$. 
Ingold, T. 2007, 'Earth, Sky, Wind, and Weather', Journal of the Royal Anthropological Institute, vol. 13, no. 1, pp. 19-38, DOI: 10.1111/j.1467-9655.2007.00401.x.

Ingold, T. 2008, 'Bindings against Boundaries: Entanglements of Life in an Open World', Environment and Planning A: Economy and Space, vol. 40, no. 8, pp. 17961810, DOI: $10.1068 / \mathrm{a} 40156$.

Ingold, T. 2010, 'Footprints through the Weather-World: Walking, Breathing, Knowing', Journal of the Royal Anthropological Institute, vol. 16, no. 1, pp. 121139, DOI: 10.1111/j.1467-9655.2010.01613.x.

Jacobus, M. 2006, 'Cloud Studies: the Visible Invisible', Gramma: Journal of Theory and Criticism, vol. 14, pp. 219-247, DOI: 10.26262/gramma.v14i0.6522.

Kidd, C., Levizzani, V. \& Bauer, P. 2009, 'A Review of Satellite Meteorology and Climatology at the Start of the Twenty-First Century', Progress in Physical Geography: Earth and Environment, vol. 33, no. 4, pp. 474-489, DOI: $10.1177 /$ 0309133309346647.

Kidder, S.Q. \& Vonder Haar, T. 1995, Satellite Meteorology: an Introduction, Academic Press, San Diego.

Kinsley, S. 2014, 'The Matter of "Virtual” Geographies', Progress in Human Geography, vol. 38, no. 3, pp. 364-384, DOI: 10.1177/0309132513506270.

LeBlanc, F. 2010, An Introduction to Stellar Astrophysics, Wiley, Chichester.

Lin, W. 2018, 'Air. Spacing the Atmosphere: the Politics of Territorialising Air', in K. Peters, P. Steinberg \& E. Stratford (eds), Territory beyond Terra, Rowman \& Littlefield, London, pp. 35-49.

Lutgens, F.K. \& Tarbuck, E.J. 2016, The Atmosphere: an Introduction to Meteorology, 13 th edn, Pearson, Hoboken.

Machine àfumée, soufflerie aérodynamique, Catalogue des Appareils Cinématographiques de la Cinémathèque Française et du CNC, last viewed on 15 December 2020, www. cinematheque.fr/fr/catalogues/appareils/collection/machine-a-fumee-soufflerieaerodynamiqueap-18-3274.html.

Magritte, R. 1929, The False Mirror, Oil on canvas, 54 x 80.9 cm, MoMa, New York, last viewed on 15 December 2020, www.moma.org/collection/works/78938.

Marey, E.J. 1901, Prisme triangulaire présentant au courant une de ses bases, quatrième et dernière version de la machine à fumée, équipée de 57 canaux, Musée d'Orsay, last viewed on 15 December 2020, www.musee-orsay.fr/fr/evenements/expositions/ archives/presentation-detaillee.html?zoom=1\&tx_damzoom_pi $1 \% 5$ BshowUid $\% 5$ $\mathrm{D}=100376 \& \mathrm{cHash}=2 \mathrm{da} 8 \mathrm{e} 4 \mathrm{~b} 58 \mathrm{~b}$.

Martin, C. 2011, 'Fog-bound: Aerial Space and the Elemental Entanglements of Body-With-World', Environment and Planning D: Society and Space, vol. 29, no. 3, pp. 454 468, DOI: 10.1068/d10609.

Massey, D. 1999, 'Space-Time, "Science" and the Relationship between Physical Geography and Human Geography', Transactions of the Institute of British Geographers, vol. 24, no. 3, pp. 261-276, DOI: 10.1111/j.0020-2754.1999.00261.x.

Mattern, S. 2017, Code and Clay, Data and Dirt: Five Thousand Years of Urban Media, University of Minnesota Press, Minneapolis.

Merriman, P. \& Pearce, L. 2017, 'Mobility and the Humanities', Mobilities, vol. 12, no. 4, pp. 493-508, DOI: 10.1080/17450101.2017.1330853.

McCormack, D. 2003, 'An Event of Geographical Ethics in Spaces of Affect', Transactions of the Institute of British Geographers, vol. 28, no. 4, pp. 488-507, DOI: 10.1111/j.0020-2754.2003.00106.x. 
McDowell, S., Steinberg, P.E. \& Tomasello, T.K. 2008, Managing the Infosphere. Governance, Technology, and Cultural Practice in Motion, Temple University Press, Philadelphia.

Oppitz, M. \& Tomsu, P. 2018, Inventing the Cloud Century - How Cloudiness Keeps Changing Our Life, Economy and Technology, Springer, Cham.

Pedgley, D.E. 2003, 'Luke Howard and His Clouds', Weather, vol. 58, no. 2, pp. 51-55, DOI: $10.1256 /$ wea.157.02.

Peters, J.D. 2015, The Marvelous Clouds. Toward a Philosophy of Elemental Media, University of Chicago Press, Chicago.

Peters, K., Steinberg, P. \& Stratford, E. (eds) 2018, Territory beyond Terra, Rowman \& Littlefield, London.

Regalado, A. 2011, 'Who Coined “Cloud Computing”?' MIT Technology Review, last viewed on 16 December 2020, www.technologyreview.com/s/425970/ who-coined-cloud-computing.

Spitzer, L. Jr. \& Schwarzschild, M. 1951, 'The Possible Influence of Interstellar Clouds on Stellar Velocities I', Astrophysical Journal, vol. 114, pp. 385-397, DOI: 10.1086/ 145478.

1953, 'The Possible Influence of Interstellar Clouds on Stellar Velocities II', Astrophysical Journal, vol. 118, pp. 106-112, DOI: 10.1086/145730.

Srnicek, N. 2017, Platform Capitalism, Polity, Cambridge.

Stengers, I. 2003, Cosmopolitics, University of Minnesota Press, Minneapolis.

Sui, D. \& DeLyser, D. 2012, 'Crossing the Qualitative-Quantitative Chasm I: Hybrid Geographies, the Spatial Turn, and Volunteered Geographic Information (VGI)', Progress in Human Geography, vol. 36, no. 1, pp. 111-124, DOI: 10.1177/ 0309132510392164.

Wang, P.K. 2013, Physics and Dynamics of Clouds and Precipitation, Cambridge University Press, Cambridge.

Ward, M. 2014, 'The Art of Writing Place', Geography Compass, vol. 8, no. 10, pp. 755-766, DOI: $10.1111 /$ gec3.12164.

Wilson, T. L., Rohlfs, K. \& Huttemeister, S. 2013, Tools of Radio Astronomy, Springer, Berlin.

World Meteorological Organization 1975, International Cloud Atlas. Volume I. Manual on the Observation of Clouds and Other Meteors, WMO, Geneva.

Wright, S., Suchet-Pearson, S., Lloyd, K., Burarrwanga, L., Ganambarr, R., Ganambarr-Stubbs, M., Ganambarr, B. \& Maymuru, D. 2020, 'Gathering of the Clouds: Attending to Indigenous Understandings of Time and Climate through Songspirals', Geoforum, vol. 108, pp. 295-304, DOI: 10.1016/ j.geoforum.2019.05.017.

Yamamoto, S. 2017, Introduction to Astrochemistry. Chemical Evolution from Interstellar Clouds to Star and Planet Formation, Springer, Tokyo. 